\section{Early alcohol use and problem drinking among students in Zambia and Uganda}

\author{
Monica H. Swahn, ${ }^{1}$ Bina Ali, ${ }^{1}$ \\ Jane Palmier, ${ }^{1}$ Nazarius Mbona \\ Tumwesigye, ${ }^{2}$ George Sikazwe, ${ }^{3,4}$ \\ Jeremiahs Twa-Twa, ${ }^{5}$ Kasirye Rogers ${ }^{6}$ \\ ${ }^{1}$ Institute of Public Health, Georgia State \\ University, Atlanta, USA; \\ 2Makerere University, School of Public \\ Health, Kampala, Uganda; \\ ${ }^{3}$ Health Promotion, Ministry of Health, \\ Lusaka, Zambia; \\ ${ }^{4}$ Department of Health Promotion, \\ University of Zambia, Lusaka, Zambia; \\ ${ }^{5}$ Ministry of Health, Kampala, Uganda; \\ 'Uganda Youth Development Link, \\ Kampala, Uganda
}

\section{Abstract}

Excessive alcohol use is a serious public health concern worldwide, but less attention has been given to the prevalence, risk and protective factors, and consequences of early alcohol use in low-income, developing countries. The purpose of this study was to determine the associations between early alcohol use, before age 13, and problem drinking among adolescents in Uganda and Zambia. Data from students in Zambia ( $\mathrm{n}=2257 ; 2004)$ and Uganda $(\mathrm{n}=3215 ; 2003)$ were obtained from the crosssectional Global School-Based Student Health Survey (GSHS). The self-administered questionnaires were completed by students primarily 13 to 16 years of age. Multiple statistical models were computed using logistic regression analyses to test the associations between early alcohol initiation and problem drinking, while controlling for possible confounding factors (e.g., current alcohol use, bullying victimization, sadness, lack of friends, missing school, lack of parental monitoring, and drug use). Results show that early alcohol initiation was associated with problem drinking in both Zambia (AOR=1.28; 95\% CI:1.02-1.61) and Uganda (AOR=1.48; 95\% CI: 1.11-1.98) among youth after controlling for demographic characteristics, risky behaviors, and other possible confounders.The study shows that there is a significant association between alcohol initiation before 13 years of age and problem drinking among youth in these two countries. These findings underscore the need for interventions and strict alcohol controls as an important policy strategy for reducing alcohol use and its dire consequences among vulnerable youth.

\section{Introduction}

Excessive alcohol use is a serious risk-factor for adverse health outcomes worldwide. ${ }^{1}$ Globally, alcohol use causes 1.8 million or $3.2 \%$ of all deaths and accounts for $4.0 \%$ of the disease burden. ${ }^{2}$ The disease burden related to alcohol use is especially great among lowincome and middle-income populations and countries, where alcohol consumption is increasing and injury rates are high due to limited implementation of public health policies and prevention strategies. ${ }^{1,2}$ A critical aspect of alcohol use is pre-teen alcohol initiation, which worsens adverse health outcomes among youth. Epidemiological studies in western countries have examined the association between early alcohol initiation and problems related to alcohol among youth, but data is lacking to study such associations in most developing countries.

Pre-teen alcohol use is of paramount concern to public health as it has been associated with alcohol dependence, ${ }^{3}$ substance use and criminal activity, ${ }^{4}$ unintentional injuries, 5,6 unplanned and unprotected sex, ${ }^{5}$ involvement in physical fights, ${ }^{7}$ and suicidal ideation and attempts. ${ }^{8-10}$ Literature on pre-teen alcohol initiation have identified gender, age, monthly income, living arrangement, attitude toward alcohol use, perceived susceptibility of alcohol use, perceived self-efficacy, peer drinking, relatives drinking, accessibility of alcohol around university, accessibility of alcohol around community, exposure to anti-alcohol campaign, ${ }^{11}$ exposure to alcohol advertising, ${ }^{11-14}$ and ownership of alcohol promotional items ${ }^{13,15}$ as significant correlates of alcohol use.

The risk of alcohol use among youth in lowincome countries is a vital public health concern. In Africa, alcohol use is related to poverty, ${ }^{16}$ road traffic crashes, ${ }^{17}$ sexual intercourse among adolescents, ${ }^{18}$ unprotect sex, ${ }^{16,19,20}$ and psychological distress. $^{21}$ To exacerbate the conditions, heavy episodic drinking is prevalent among young adults in several African countries. ${ }^{22}$ For example, more than one in every three Zambian adolescents have ever drunk alcohol, ${ }^{23}$ and Uganda has been noted as having the highest alcohol per capital consumption in the world. ${ }^{22}$

The current study uses nationally representative samples to examine the associations between pre-teen alcohol use initiation and drinking problems among Zambian and Ugandan youth. The study controls for demographic characteristics and other potential confounding variables that have been linked to alcohol use, substance use or suicidal behaviors. $^{24-28}$
Correspondence: Monica H. Swahn, Institute of Public Health, Georgia State University, P0 Box 3995, Atlanta, GA 30302-3995, USA.

Tel. + 1.404.4131148.

E-mail: mswahn@gsu.edu

Key words: alcohol use, problem drinking, Zambia, Uganda.

Acknowledgment: the authors are grateful to the Ministries of Health in Lusaka, Zambia and in Kampala, Uganda for their willingness to share their data and for collaborating on this manuscript.

Received for publication: 13 September 2010. Accepted for publication: 17 May 2011.

This work is licensed under a Creative Commons Attribution NonCommercial 3.0 License (CC BYNC 3.0).

(C) Copyright M.H. Swahn et al., 2011

Licensee PAGEPress, Italy

Journal of Public Health in Africa 2011; 2:e20

doi:10.4081/jphia.2011.e20

\section{Materials and Methods}

The current study is based on the Global School-based Student Health Survey (GSHS), ${ }^{29}$ developed and supported by the World Health Organization in collaboration with the United Nations Children's Fund, the United Nations Educational, Scientific, and Cultural Organization, the Joint United Nations Programme on HIV/AIDS, and with technical assistance from the Centers for Disease Control and Prevention. The goal of the GSHS is to provide data on health behaviors and relevant risk and protective factors among students across all regions served by the United Nations. Country specific questionnaires, fact sheets, public-use data files, documentation and reports are publicly available from the Centers for Disease Control and Prevention and the World Health Organization and have been described elsewhere. ${ }^{23,30-32}$

In brief, the GSHS consists of a self-administered questionnaire, administered primarily to students 13-16 years of age. The survey uses a standardized scientific sample selection process, common school-based methodology, and a combination of core questionnaire modules, core-expanded questions, and countryspecific questions. This study conducted secondary analysis of the restricted data files for Zambia and Uganda. Data were collected from Zambian students ( $\mathrm{n}=2257)$ in 2004 and from Ugandan students $(n=3215)$ in 2003. The school response rates were $94 \%$ for Zambia and $80 \%$ for Uganda, and student response rate were $75 \%$ for Zambia and 76\% for Uganda, yielding an overall response rates of $70 \%$ for Zambia and $69 \%$ for Uganda. IRB approvals 
was obtained from Georgia State University to conduct these analyses.

\section{Measures}

In Uganda, prior to asking any of the alcohol-related questions, participants were instructed to think of alcohol to include drinking Tonto, Mwenge, crude, Waragi, Kasese, Lira lira, Uganda Waragi, Whisky, Bond 7, Tyson, Malwa, Kwete, Komek, Bell Beer, Special, Pilsoner, Club, Chairman (ESB), Eagle, and Citizen and that drinking alcohol does not include drinking a few sips of church wine for religious purposes. Similarly, students in Zambia were given the following instructions when responding to the alcoholrelated questions to include drinking Mosi, Castle, Katata, Kachasu, or Katubi and that drinking alcohol does not include drinking a few sips of wine for religious purposes.

The outcome measure was problem drinking, defined as the number of times the students had a hang-over, felt sick, got into trouble with family or friends, missed school, or got into fights due to alcohol use. The measure was assessed on a 4-item scale ranging from 0 times to 10 or more times. Responses to either outcome measure were dichotomized to reflect none versus any problem drinking behavior.

The main independent variable was alcohol initiation before or at age 13 years old, which was measured by students' response on their age at which they had their first drink of alcohol other than a few sips. The 7-item scale ranged from never drinking to initiating drinking at 16 years of age or older. All analyses were limited to students 14 years of age and older. The analyses controlled for the following potential confounders: current alcohol use, bullying victimization, sadness, lack of friends, missing school, lack of parental monitoring, and illicit drug use. Each preceding variable was dichotomized to reflect none versus any involvement or exposure to the particular factor measured. Table 1 describes each measure and its prevalence within each country among students age 14 and older.

\section{Analysis}

Logistic regression analyses were conducted to identify odds of alcohol initiation $\leq 13$ years old after controlling for sex, age, current alcohol use, bully victimization, sadness, lack of friends, missing school, lack of parental monitoring, and illicit drug use. Logistic regression analyses were also computed to determine the associations between alcohol initiation $\leq 13$ years old and problem drinking. Model 1 included sex, age, and alcohol initiation $\leq 13$ years age. Model 2 included variables from Model 1 along with bully victimization, sadness, lack of friends, missing school, lack of parental monitoring, and illicit drug use. For variables where the amount of missing data exceeded five percent, the commonly used missing-indicator method was applied. ${ }^{33,34}$ In this method, a dummy category is created to reflect the missing data and thereby including nearly all participants in the analyses rather than omitting them using the default listwise deletion used in the logistic regression computation. While no statistical findings or associations are reported on the missing data, the Odds Ratio would be interpreted as the risk for the outcome for those with missing data relative to the reference category. Analyses were conducted with the SAS 9.1 and SUDAAN 10.0 statistical software packages to accommodate the sampling design, and produce weighted estimates.

\section{Results}

The prevalence of problem drinking and other factors examined in both Zambia and Uganda are presented in Table 1.

Results from logistic regression indicate that early alcohol use initiation was most strongly associated with current alcohol use in Zambia (AOR=6.78; 95\% CI: 4.28-10.76) and in Uganda (AOR=14.37; 95\% CI: 14.37-20.06) (Table 2). Moreover there were no differences by sex in terms of reporting pre-teen drinking initiation in either country. In Uganda, missed school without excuse and also lack of parental monitoring were significant factors associated with early alcohol use.

Logistic regressions were also conducted to determine the associations between alcohol use initiation, other factors and problem drinking using two separate models. Model 1 included sex, age, and alcohol initiation before age 13. In Zambia, in model 1, boys had significantly lower risk than girls for problem drinking (AOR=0.69; 95\% CI: 0.49- 0.97), age 14 was a significant risk factor for problem drinking (AOR=1.57; 95\% CI: 1.04- 2.37) compared to age 16 , and alcohol initiation before age 13 was a significant risk factor for problem drinking (AOR=2.66; 95\% CI: 2.11- 3.34). In Uganda, in Model 1, alcohol initiation before age 13 was the only risk factor for problem drinking $(\mathrm{AOR}=2.97$; 95\% CI: 2.34- 3.77) (Table 3).

Model 2 of the logistic regression analysis included sex, age, alcohol initiation before age 13, current alcohol use, bully victimization, sadness, no friends, missing school, no parental monitoring, and illicit drug use. Results show that after controlling for these risk factors, alcohol initiation was significant-

Table 1. Variable description and prevalence of factors examined.

\begin{tabular}{|c|c|c|c|}
\hline Variable name & Variable description & $\begin{array}{l}\text { Zambia } \\
\mathrm{n}=2257 \\
\text { weighted \% }\end{array}$ & $\begin{array}{l}\text { Uganda } \\
\text { n=3215 } \\
\text { weighted \% }\end{array}$ \\
\hline Early alcohol use initiation & $\begin{array}{l}\text { Students who were } 13 \text { years or younger when they had their first drink of alcohol } \\
\text { other than a few sips. }\end{array}$ & $36.4 \%$ & $21.6 \%$ \\
\hline Problem drinking & $\begin{array}{l}\text { Students who ever had a hang-over, felt sick, got into trouble with family or friends, } \\
\text { missed school, or got into fights, as a result of drinking alcohol. }\end{array}$ & $45.1 \%$ & $21.5 \%$ \\
\hline Current alcohol use & $\begin{array}{l}\text { Students who had at least one drink containing alcohol on one or more } \\
\text { days during the past } 30 \text { days. }\end{array}$ & $42.6 \%$ & $24.1 \%$ \\
\hline Bullying victimization & Students who were bullied on one or more days in the past 30 days. & $63.1 \%$ & $44.3 \%$ \\
\hline Sadness & $\begin{array}{l}\text { Students who felt so sad or hopeless almost every day for two weeks or more } \\
\text { in a row that they stopped doing their usual activities during the past } 12 \text { months. }\end{array}$ & $53.3 \%$ & $51.4 \%$ \\
\hline No friends & Students who have no close friends. & $15.7 \%$ & $14.7 \%$ \\
\hline Missed school & $\begin{array}{l}\text { Students who missed classes or school without permission on one } \\
\text { or more days during the past } 30 \text { days. }\end{array}$ & $58.5 \%$ & $46.4 \%$ \\
\hline No parental monitoring & $\begin{array}{l}\text { Students whose parents or guardians really knew what they were doing with } \\
\text { their free time in the past } 30 \text { days. }\end{array}$ & $35.2 \%$ & $29.8 \%$ \\
\hline Illicit drug use & Students who used drugs during their life.* & $36.7 \%$ & $31.0 \%$ \\
\hline
\end{tabular}

*The types of drugs included in the questions differed in the two countries. In Uganda the question was asked as follows "During your life, how many times have you used drugs, such as marijuana (njaga or bangi) or opium (njaye) or sniffed aviation fuel? In Zambia the question was asked as follows: During your life, how many times have you used marijuana or hashish (also called daga, ibange, mbanje, or chamba)? 
ly associated with problem drinking (AOR= 1.28; 95\% CI: $1.02-1.61 ; \mathrm{AOR}=1.48 ; 95 \% \mathrm{CI}$ : 1.11-1.98) in Zambia and Uganda, respectively. Other significant factors associated with problem drinking were also identified. Current alcohol use, experience with bully victimization, sadness, missing school, and illicit drug use were significant risk factors for problem drinking among youth in both Zambia and Uganda.

\section{Discussion}

This study examined the association between pre-teen alcohol initiation and problem drinking among youth in Zambia and Uganda. The results show that early alcohol use is a significant risk factor for problem drinking among Zambian and Ugandan youth after controlling for potential environmental confounders. This finding is supported by previous studies, primarily conducted in the U.S., that have found that early alcohol use is associated with risk-taking and other behavior and mental health problems in adolescence as well as later in life in. . $^{3-10}$

Moreover in this study, current alcohol use, experience with bully victimization, sadness, missing school, and illicit drug use were significant risk factors for problem drinking among youth in both Zambia and Uganda. These findings suggest that other risky behaviors are accompanying behaviors related to drinking, which need to be incorporated in multi-component interventional strategies to reduce substance use among Zambian and Ugandan youth. This study also found that problem drinking is a greater risk among Zambian girls than boys, which is supported by a previous study on Zambian youth that reported higher prevalence of drinking alcohol among girls than boys. ${ }^{23}$ Generally, current alcohol use is more common among boys than girls; therefore, this finding calls for possible sex-specific research and intervention to reduce drinking behavior and problems among girls in Zambia.

Our study noted that youth in Zambia and Uganda experience similar risk factors for problem drinking. Moreover, the study found that alcohol problem is associated with several environmental risk factors that need to be targeted through interventional strategies. The findings of the study urges the need for multicomponent intervention to reduce pre-teen alcohol use because alcohol use in Africa has been linked to poverty and risky sexual practices, ${ }^{16,18-20}$ which worsen already dire social and personal conditions. Also, including or amplifying strategies to increase protective factors, such as school attendance, parental or guardian connectedness, peer support at school, and parental supervision ${ }^{35}$ are critical in preventing adverse health outcomes among African youth.

There are several limitations that should be considered when interpreting the findings of this study. The study is based on self-reported data of students in Zambia and Uganda. Therefore, the findings cannot be generalized to youth who are not attending school or other populations. The surveys were administered in 2003 and 2004, hence the findings do not reflect any changes that may have taken place, such as policies and strategies that affect preteen alcohol use after the surveys were conducted. Also, the findings are based on crosssectional analysis, and temporal relationships cannot be determined nor can causality be inferred. Other factors may be related to alcohol use among youth, such as mental health and physical and sexual violence, ${ }^{36}$ that were not included in the analysis. Lastly, several

Table 2. Multivariate associations between sex, age, alcohol risk factors and early alcohol use initiation among students 14 years of age and older in Zambia and Uganda.

\begin{tabular}{|c|c|c|}
\hline & $\begin{array}{c}\text { Zambia } \\
\operatorname{AOR}(95 \% \mathrm{CI})\end{array}$ & $\begin{array}{l}\text { Uganda } \\
\text { AOR }(95 \% \mathrm{CI})\end{array}$ \\
\hline $\begin{array}{l}\text { Sex } \\
\text { Boys } \\
\text { Girls }\end{array}$ & $\begin{array}{l}(0.82-1.52) \\
1.00\end{array}$ & $\begin{array}{c}1.24(0.91-1.68) \\
1.00\end{array}$ \\
\hline $\begin{array}{l}\text { Age } \\
\qquad 14 \\
15 \\
>16\end{array}$ & $\begin{array}{c}1.56(1.11-2.19) \\
1.14(0.80-1.62) \\
1.00\end{array}$ & $\begin{array}{c}1.64(1.10-2.45) \\
1.36(1.05-1.76) \\
1.00\end{array}$ \\
\hline $\begin{array}{l}\text { Current alcohol use } \\
\text { Bully victimization }\end{array}$ & $\begin{array}{c}6.78(4.28-10.76) \\
1.30(0.92-1.84)\end{array}$ & $\begin{array}{c}14.37(10.29-20.06) \\
1.15(0.83-1.59)\end{array}$ \\
\hline $\begin{array}{l}\text { Sadness } \\
\text { No friends }\end{array}$ & $\begin{array}{l}0.84(0.63-1.12) \\
1.22(0.77-1.96)\end{array}$ & $\begin{array}{l}0.99(0.77-1.28) \\
0.84(0.46-1.54)\end{array}$ \\
\hline Missed school & $1.20(0.86-1.68)$ & $1.41(1.08-1.85)$ \\
\hline No parental monitoring & $1.03(0.78-1.39)$ & $1.71(1.22-2.39)$ \\
\hline Illicit drug use & $1.18(0.93-1.51)$ & $0.99(0.64-1.54)$ \\
\hline
\end{tabular}

AOR, adjusted odds ratios including all variables listed in the table.

Table 3. Multivariate associations between sex, age, early alcohol use initiation and problem drinking among students 14 years of age and older in Zambia and Uganda.

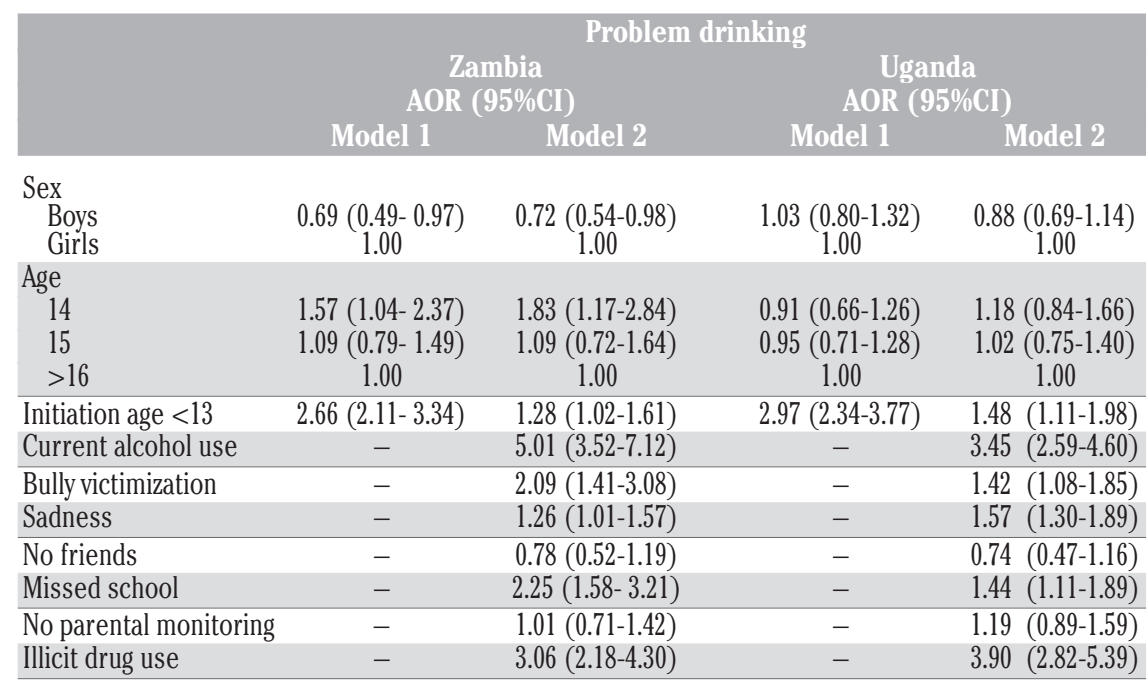

AOR, adjusted odds ratios including all variables listed in the table. variables had a substantial amount of missing data and the missing-indicator method was applied $^{34}$ to include participants with partially missing data in the analyses. Such method, regression coefficients and impacted the ( ${ }^{37}$ Few investigations have examine problem drinking among youth in Subconducted so far, primarily in the U.S., indicate that early alcohol use initiation is a significant problem, and the current analyses underscore that early alcohol use initiation is a significant public health problem also in Zambia and Uganda. While studies conducted primarily in the U.S. provide important information about the relationship between early alcohol use initiation and problem drinking, analyses conducted in different countries and settings are needed to provide additional perspectives and while commonly used, may have biased some Saharan Africa. The studies that have been 
context to potential cultural and regional differences that impact early substance use and its consequences. In this study, comparisons of two nationally representative samples of youth in Zambia and Uganda highlight similarities and differences in the associations between early alcohol use and problem drinking. These findings, placed into context, can assist the development and implementation of prevention and intervention strategies that seek to reduce the harmful consequences of early alcohol use among vulnerable youth. Meanwhile, our findings support increased efforts to develop and implement evidence-based interventions to prevent and reduce early alcohol use initiation among vulnerable populations with high levels of current alcohol use.

\section{References}

1. Rehm J, Mathers C, Popova S, et al. Global burden of disease and injury and economic cost attributable to alcohol use and alcoholuse disorders. Lancet 2009;373:2223-33.

2. Benegal V, Borges G, Casswell S, et al. Alcohol and injury in Emergency Departments: Summary of the Report from the WHO Collaborative Study on Alcohol and Injuries 2007. Available from: http:/www.who.int/substance_abuse/publications/alcohol_injury_summary.pdf.

3. Hingson R, Heeren T, Winter MR. Age at drinking onset and alcohol dependence: age at onset, duration, and severity. Arch Pediatr Adolesc Med 2006;160:739-46.

4. Ellickson PL, Tucker JS, Klein DJ. Ten-year prospective study of public health problems associated with early drinking. Pediatrics 2003;111:949-55.

5. Hingson R, Heeren T, Jamanka A, Howland J. Age of drinking onset and unintentional injury involvement after drinking. JAMA 2000;284:1527-33.

6. Hingson R, Heeren T, Zakocs R, Winter M, Wechsler $\mathrm{H}$. Age of first intoxication, heavy drinking, driving after drinking and risk of unintentional injury among U.S. college students. J Stud Alcohol 2003;64:23-31.

7. Hingson R, Heeren T, Zakocs R. Age of drinking onset and involvement in physical fights after drinking. Pediatrics 2001;108:872-77.

8. Cho H, Hallfors DD, Iritani BJ. Early initiation of substance use and subsequent risk factors related to suicide among urban high school students. Addict Behav 2007;32:162839.

9. Swahn, MH, Bossarte RM. Gender, early alcohol use, and suicide ideation and attempts: Findings from the 2005 Youth Risk Behavior Survey. J Adolesc Health 2007;41:175-81.
10. Swahn, MH, Bossarte RM, Sullivent EE. Age of alcohol use initiation, suicidal behavior, and peer and dating violence victimization and perpetration among high-risk seventhgrade adolescents. Pediatrics 2008;121:297305.

11. Vantamay S. Alcohol consumption among university students: applying a social ecological approach for multi-level preventions. Southeast Asian J Trop Med Public Health 2009;40:354-69.

12. Ellickson PL, Collins RL, Hambarsoomian K, McCaffrey DF. Does alcohol advertising promote adolescent drinking? Results from a longitudinal assessment. Addiction 2005; 100:235-46.

13. Hurtz SQ, Henriksen L, Wang Y, et al. The relationship between exposure to alcohol advertising in stores, owning alcohol promotional items, and adolescent alcohol use. Alcohol Alcoholism 2007;42:143-9.

14. Snyder LB, Milici FF, Slater M, et al. Effects of alcohol advertising exposure on drinking among youth. Arch Pediatr Adolesc Med 2006;160:18-24.

15. McClure AC, Cin SD, Gibson J, Sargent JD. Ownership of alcohol-branded merchandise and initiation of teen drinking. Am J Prev Med 2006;30:277-83.

16. Kalichman SC, Simbayi LC, Kaufman M, et al. Alcohol use and sexual risks for HIV/AIDS in sub-Saharan Africa: systematic review of empirical findings. Prev Sci 2007;8:141-51.

17. Hassan S, Macharia WM, Atinga J. Self reported alcohol use in an urban traffic trauma population in Kenya. East Afr Med J 2005;82:144-47.

18. Siziya S, Muula AS, Kazembe, LN, Rudatsikira E. Harmful lifestyles' clustering among sexually active in-school adolescents in Zambia. BMC Pediatr 2008;8:6.

19. Coldiron ME, Stephenson R, Chomba E, et al. The relationship between alcohol consumption and unprotected sex among known HIV-discordant couples in Rwanda and Zambia. AIDS Behav 2008;12:594-603.

20. Weiser SD, Leiter K, Heisler M, et al. A population based study on alcohol and high-risk sexual behaviors in Botswana. PLoS Med 2006;3:e392.

21. Page RM, Hall CP. Psychosocial distress and alcohol use as factors in adolescent sexual behavior among sub-Saharan African adolescents. J Sch Health 2009;79:369-79.

22. World Health Organization. Global status report on alcohol 2004. Available from: http://www.who.int/substance_abuse/publications/global_status_report_2004_overvie w.pdf.

23. Muula AS, Kazembe LN, Rudatsikira E, Siziya S. Suicidal ideation and associated factors among in-school adolescents in Zambia. Tanzan Health Res Bull 2007; 9:202-6.
24. Department of Health and Human Services. The Surgeon General's call to action to prevent suicide. 1999, Department of Health and Human Services, Washington, DC, USA. Available from: http:/www.surgeongeneral. gov/library/calltoaction/default.htm.

25. Borowsky IW, Ireland M, Resnick MD. Adolescent suicide attempts: risks and protectors. Pediatrics 2001;107:485-93.

26. Brady J. The associations between alcohol misuses and suicidal behavior. Alcohol Alcoholism 2006;41:473-78.

27. Bridge JA, Golstein TR, Brent DA. Adolescent suicide and suicidal behavior. J Child Psychol Psychiatry 2006;47:372-94.

28. Moscicki EK. Epidemiology of completed and attempted suicide: toward a framework for prevention. Clin Neurosci Res 2001;1: 310-23.

29. Centers for Disease Control and Prevention. 2009 Global School-based Student Health Survey. Available from: http://www.cdc. gov/GSHS/.

30. Rudatsikira E, Siziya S, Kazembe LN, Muula AS. Prevalence and associated factors of physical fighting among school-going adolescents in Namibia. Ann Gen Psychiatry 2007;6:18.

31. Swahn MH, Bossarte RM, Elimam DM, et al. Prevalence and correlates of suicidal ideation and physical fighting: a comparison between students in Botswana, Kenya, Uganda, Zambia and the USA. Int Public Health J 2010;2:195-205.

32. Swahn MH, Bossarte RM, Gaylor E, et al. Hunger and risk for emotional and behavioral problems: a comparison between students in Botswana, Kenya, Uganda and Zambia. Int Public Health J 2010;2:185-94.

33. Cheng ATA, Gau SF, Chen THH, et al. A 4year longitudinal study on risk factors for alcoholism. Arch Gen Psychiatry 2004;61: 184-91.

34. Miettinen OS. Theoretical epidemiology. 1985, John Wiley \& Sons, Inc., New York, NY, USA.

35. Peltzer K. Health behavior and protective factors among school children in four African countries. Int $\mathrm{J}$ Behav Med 2009;16:172-80.

36. Brown DW, Riley L, Butchart A, et al. Exposure to physical and sexual violence and adverse health behaviours in African children: Results from the Global Schoolbased Student Health Survey. Bull World Health Organ 2009;87:447-55.

37. Faris PD, Ghali WA, Brant R, et al. Multiple imputation versus data enhancement for dealing with missing data in observational health care outcome analyses. J Clin Epidemiol 2002;55:184-91. 